\title{
Sex differences in the association between serum uric acid levels and cardiac hypertrophy in patients with chronic kidney disease
}

\author{
Ryota Yoshitomi ${ }^{1}$, Akiko Fukui ${ }^{2}$, Masaru Nakayama ${ }^{2}$, Yoriko Ura ${ }^{2}$, Hirofumi Ikeda ${ }^{2}$, Hideyuki Oniki ${ }^{3}$, \\ Takuya Tsuchihashi ${ }^{3}$, Kazuhiko Tsuruya ${ }^{1}$ and Takanari Kitazono ${ }^{1}$
}

\begin{abstract}
Several studies have documented an association between serum uric acid (SUA) concentration and cardiac hypertrophy in hypertensive patients; however, the association remains unclear in chronic kidney disease (CKD) patients. If there is an association between SUA and hypertrophy in these patients, it is unknown whether the association is different between men and women. Our aim in this study is to determine whether SUA is associated with cardiac hypertrophy in CKD patients, focusing on any sex differences. Two hundred sixteen CKD patients (117 men and 99 women) were enrolled in this crosssectional study. Patients prescribed uric acid-lowering agents and those with congestive heart failure, valvular heart disease, or ischemic heart disease were excluded from this study. Left ventricular mass index (LVMI) and left ventricular hypertrophy (LVH) were assessed using echocardiography. The prevalence of LVH was $58 \%$ in men and $47 \%$ in women. In multivariate linear regression analysis, SUA levels did not correlate with LVMI in men, whereas SUA was independently associated with LVMI in women $(\beta=0.27, P=0.02)$. Multivariate logistic regression analysis also revealed that diabetes mellitus (odds ratio (OR), 4.41; $P=0.01$ ) was associated with LVH in men, whereas age (OR, 1.13; $P<0.01)$, hypertension (OR, 7.38; $P=0.03)$ and SUA (OR, 1.91; $P=0.03$ ) were associated with LVH in women. In female CKD patients, SUA levels were associated with LVMI and LVH, whereas there was no association in male patients. These observations suggest that an association between SUA levels and the development of cardiac hypertrophy is more likely in women than in men.

Hypertension Research (2014) 37, 246-252; doi:10.1038/hr.2013.134; published online 3 October 2013
\end{abstract}

Keywords: cardiac hypertrophy; chronic kidney disease; hyperuricemia; sex difference

\section{INTRODUCTION}

Patients with chronic kidney disease (CKD) have high cardiovascular (CV) morbidity and mortality, and the presence of CKD worsens CV disease outcomes. ${ }^{1}$ Cardiac hypertrophy, that is, left ventricular hypertrophy (LVH) or increased left ventricular mass index (LVMI), is known to be a powerful, independent risk factor for future CV morbidity and mortality in patients with essential hypertension, as well as in the general population. ${ }^{2-5}$ The prevalence of cardiac hypertrophy increases with declining renal function in CKD patients not undergoing dialysis and cardiac hypertrophy is independently associated with adverse CV events in these patients. ${ }^{6-13}$ Thus, cardiac hypertrophy may be a major adverse $\mathrm{CV}$ consequence of CKD.

Several epidemiologic studies have suggested a positive association between serum uric acid (SUA) levels and CV disease in the general population, ${ }^{14-17}$ in hypertensive patients ${ }^{18,19}$ and in CKD patients. $^{20,21}$ It has also been reported that higher SUA levels are associated with cardiac hypertrophy in hypertensive patients. ${ }^{22-26}$ As approximately two-thirds of SUA is excreted through the kidneys, CKD patients develop hyperuricemia as the glomerular filtration rate declines. ${ }^{27}$ It has been reported that high SUA is associated with cardiac hypertrophy in renal transplant recipients, ${ }^{28}$ but very few studies have examined the relationship between SUA levels and cardiac hypertrophy in CKD patients. ${ }^{29}$ Moreover, studies of sex differences in the relationship between SUA levels and CV disease are conflicting. Some studies have shown that SUA levels correlate significantly with cardiac hypertrophy only in female hypertensive patients, ${ }^{22,23}$ whereas another report found a significant association between SUA and cardiac hypertrophy only in male hypertensive patients. ${ }^{26}$ To date, there have been no studies of sex differences in the relationship between SUA and cardiac hypertrophy in CKD patients. Thus, we aimed to elucidate the association between SUA levels and

${ }^{1}$ Department of Medicine and Clinical Science, Graduate School of Medical Sciences, Kyushu University, Fukuoka, Japan; ${ }^{2}$ Division of Nephrology and Clinical Research Institute, Department of Internal Medicine, National Kyushu Medical Center Hospital, Fukuoka, Japan and ${ }^{3}$ Division of Hypertension and Clinical Research Institute, Department of Internal Medicine, National Kyushu Medical Center Hospital, Fukuoka, Japan

Correspondence: Dr M Nakayama, Division of Nephrology and Clinical Research Institute, Department of Internal Medicine, National Kyushu Medical Center Hospital, 1-8-1 Jigyohama, Chuo-ku, Fukuoka 810-8563, Japan.

E-mail: mnaka@kyumed.jp

Received 2 May 2013; revised 8 August 2013; accepted 8 September 2013; published online 3 October 2013 
cardiac hypertrophy in patients with $\mathrm{CKD}$, focusing especially on the sex differences in this association.

\section{METHODS}

In this cross-sectional study, we enrolled 216 patients with CKD not on dialysis, who were admitted to our hospital for evaluation and education of CKD. Patients prescribed uric acid-lowering agents and those with congestive heart failure, valvular heart disease, ischemic heart disease or local asynergy on echocardiogram were excluded from this study.

All patients provided written informed consent to the protocol, which was approved by the Ethics Committee of the National Kyushu Medical Center Hospital. Blood samples were obtained from admitted patients in the early morning after an overnight fast for measurement of serum creatinine (SCr), C-reactive protein, hemoglobin ( $\mathrm{Hb})$, SUA and serum phosphorus levels. Daily proteinuria was also measured. The estimated glomerular filtration rate (eGFR; $\mathrm{ml} \mathrm{min}{ }^{-1}$ per $1.73 \mathrm{~m}^{2}$ ) was calculated using the Modification of the Diet in Renal Disease equation for Japanese patients: $194 \times \mathrm{SCr}^{-1.094} \times \mathrm{age}^{-0.287}$ $\times 0.739$ (if female). ${ }^{30}$

All enrolled patients were interviewed and clinically examined at presentation. Their medical histories and outpatient records were also evaluated in detail. Demographic information (age and sex), medication history, and atherosclerotic risk factors (hypertension, history of smoking, dyslipidemia and diabetes mellitus) at presentation were recorded for each patient. Hypertension was defined as systolic blood pressure $\geqslant 140 \mathrm{~mm} \mathrm{Hg}$ or diastolic blood pressure $\geqslant 90 \mathrm{~mm} \mathrm{Hg}$, or use of antihypertensive drugs. Dyslipidemia was defined as plasma triglycerides $\geqslant 150 \mathrm{mg} \mathrm{dl}^{-1}$, plasma low-density lipoprotein cholesterol $\geqslant 140 \mathrm{mg} \mathrm{dl}^{-1}$, plasma high-density lipoprotein cholesterol $<40 \mathrm{mg} \mathrm{dl}^{-1}$ or the use of lipid-lowering drugs based on a history of dyslipidemia. Diabetes mellitus was defined as previous or current plasma fasting glucose $\geqslant 126 \mathrm{mg} \mathrm{dl}^{-1}$ or the use of hypoglycemic agents. Cigarette smoking was evaluated as current or past. Body mass index was calculated as weight in $\mathrm{kg}$ divided by height in $\mathrm{m}^{2}$. Blood pressure was measured at three separate times on the second day of hospitalization, with patients in a sitting position. The average of the three readings was recorded.

Left ventricular mass (LVM) was calculated from M-mode records taken on parasternal long-axis images, according to the following formula (derived by Reichek and Devereux $\left.{ }^{31}\right): \operatorname{LVM}=1.04\left(\left[\right.\right.$ IVSd + LVPWd $\left.+\mathrm{LVDd}^{3}-\mathrm{LVDd}^{3}\right)$ -13.6, where IVSd and LVPWd are the thickness of the interventricular septum and of the posterior wall of the left ventricle (LV) in diastole, respectively, and LVDd is the diameter of the LV in diastole. LVMI was expressed as LVM per square meter of body surface area, calculated by the $\mathrm{Du}$ Bois formula: ${ }^{32}$ body surface area $=$ weight $^{0.425} \times$ height $^{0.725} \times 0.007184$

We defined LVH as LVMI of $134 \mathrm{~g} \mathrm{~m}^{-2}$ or greater for males and $110 \mathrm{~g} \mathrm{~m}^{-2}$ or greater for females. ${ }^{33}$ Percent fractional shortening was calculated as (LVDdLVDs)/LVDd $\times 100$.

\section{Statistical analysis}

Continuous data are expressed as either the mean \pm s.d. or the median (interquartile range), depending on their distribution. Categorical data are expressed as numbers (with \%). The significance of differences between female $<45$ years old and $\geqslant 45$ years old was examined using the $\chi^{2}$-test for categorical data, the Wilcoxon rank sum test for nonparametric data and the unpaired Student's $t$-test for parametric data. Correlation coefficients were calculated according to Pearson's method.

Demographic, traditional, and non-traditional risk factors, serological data, LVMI, and the prevalence of LVH were compared across quartiles of SUA levels using the $\chi^{2}$-test for categorical data, analysis of variance for continuous variables that are approximately normally distributed, and the Kruskal-Wallis test for skewed continuous variables analysis, followed by the Dunnett's test. A linear regression analysis was performed to elucidate the associations between LVMI and traditional and non-traditional risk factors. Covariates associated with LVMI in univariate analysis were analyzed by multivariate analysis to determine the independent risk factors for LVMI. A logistic regression model was also applied to elucidate the traditional and nontraditional risk factors associated with LVH. Covariates associated with LVH that were significant in univariate analysis were selected as risk factors in multivariate analysis. The odds ratio and the $95 \%$ confidence interval were calculated for each variable. Data were analyzed using the JMP9 statistical package (SAS Institute, Cary, NC, USA). A $P$-value below 0.05 indicated a significant difference.

\section{RESULTS}

The median age of the 216 patients (117 men and 99 women) in this study was 61 years (range, 30-75 years). The primary causes of renal disease were chronic glomerulonephritis (44\%, 95 patients), diabetic nephropathy (30\%, 65 patients), hypertensive nephrosclerosis (15\%, 32 patients), other defined causes $(8 \%, 17$ patients) and unknown (3\%, 7 patients).

The clinical characteristics of the patients according to CKD stage are summarized in Table 1. The prevalence of hypertension, diabetes mellitus, smoking and dyslipidemia was significantly higher with advancing CKD stages. In addition, 121 patients (56\%) had been treated with angiotensin-converting enzyme inhibitors (ACEIs) and/ or angiotensin II receptor blockers (ARBs), and this percentage was higher in advanced CKD stages. The percentage of patients receiving diuretics was also higher in more advanced CKD stages. Daily proteinuria in patients with CKD stages 4 and 5 was significantly higher than in patients with CKD stages 1 and 2. As kidney function declined, $\mathrm{Hb}$ levels decreased significantly, whereas SUA levels significantly increased in both sexes. LVMI was higher in more advanced CKD stages in both sexes. LVH was found in $53 \%$ of all subjects, with a significantly higher prevalence as kidney function decreased.

The study population was divided into quartiles by SUA level for each sex, as shown in Table 2a (men) and Table 2b (women). Among the male patients, the prevalence of hypertension was significantly higher with ascending SUA quartiles. No difference in systolic or diastolic blood pressure was found across quartiles. The eGFR values of patients in the second to fourth quartiles were significantly lower than those of patients in the first quartile. Figure 1 shows LVMI and prevalence of LVH according to quartiles of SUA in men. LVMI values were higher in fourth quartile patients than in first quartile patients. The prevalence of LVH did not increase significantly with ascending quartiles.

Among the female patients, patients in the fourth quartile had a higher median age than did those in the first quartile. The prevalence of hypertension and diabetes mellitus increased significantly with ascending quartiles. Patients in the third and fourth quartiles had significantly higher systolic blood pressure than those in the first quartile. The prevalence of ACEIs and/or ARBs and diuretic use was significantly higher with ascending quartiles. Patients in the second and fourth quartiles had significantly lower $\mathrm{Hb}$ compared with those in the first quartile. Patients in the third and fourth quartiles had significantly lower eGFR compared with those in the first quartile. As shown in Figure 2, LVMI was significantly higher in patients in the third and fourth quartiles than in those in the first quartile and the prevalence of LVH increased significantly with ascending quartiles. Table 3 shows the demographics, comorbidities, laboratory data and cardiac hypertrophy indices for females $<45$ years of age and for those $\geqslant 45$ years of age. Female subjects $\geqslant 45$ years of age had significantly higher SUA and LVMI values, and a higher prevalence of LVH than did younger women. In addition, eGFR values in female subjects $\geqslant 45$ years of age were significantly lower than in those $<45$ years of age.

Figure 3 shows the relationship between SUA and LVMI in men and women. In both sexes, LVMI was positively correlated with SUA levels $\left(R^{2}=0.06, P<0.01\right.$ in men; $R^{2}=0.28, P<0.01$ in women). 
Table 1 Clinical characteristics of patients according to chronic kidney disease stage

\begin{tabular}{|c|c|c|c|c|c|c|}
\hline & $A / /(\mathrm{n}=216)$ & CKD stages $1-2(\mathrm{n}=58)$ & CKD stage $3(\mathrm{n}=71)$ & CKD stage $4(n=46)$ & CKD stage $5(n=41)$ & P-values \\
\hline Age & $61(49-70)$ & $48(40-59)$ & $64(51-72)^{*}$ & $64(60-70)^{*}$ & $64(57-73)^{*}$ & $<0.01$ \\
\hline Male & $117(54)$ & $23(40)$ & $44(62)$ & $24(52)$ & $26(63)$ & 0.04 \\
\hline $\mathrm{SBP}(\mathrm{mm} \mathrm{Hg})$ & $134 \pm 20$ & $119 \pm 14$ & $134 \pm 21^{*}$ & $136 \pm 16^{*}$ & $151 \pm 16^{*}$ & $<0.01$ \\
\hline $\mathrm{DBP}(\mathrm{mm} \mathrm{Hg})$ & $76 \pm 11$ & $72 \pm 10$ & $76 \pm 11$ & $76 \pm 12$ & $80 \pm 10^{*}$ & $<0.01$ \\
\hline Diabetes mellitus & $86(40)$ & $4(7)$ & $32(45)$ & $25(54)$ & $25(61)$ & $<0.01$ \\
\hline ACEls and/or ARBs & $121(56)$ & $12(21)$ & $45(63)$ & $35(76)$ & $29(71)$ & $<0.01$ \\
\hline Diuretics & $51(24)$ & $2(3)$ & $17(24)$ & $13(28)$ & $19(24)$ & $<0.01$ \\
\hline Body mass index $\left(\mathrm{kg} \mathrm{m}^{-2}\right)$ & $22.1(20.1-25.1)$ & $22.2(19.9-24.4)$ & $22.0(20.5-24.7)$ & $22.8(20.2-26.1)$ & $22.0(20.7-24.1)$ & 0.88 \\
\hline Proteinuria $\left(\right.$ g day $\left.^{-1}\right)$ & $1.3(0.5-3.7)$ & $0.7(0.3-1.6)$ & $1.5(0.2-4.1)$ & $1.2(0.4-4.7)^{* *}$ & $2.6(1.1-5.3)^{*}$ & $<0.01$ \\
\hline Serum albumin $\left(\mathrm{g} \mathrm{dl}^{-1}\right)$ & $3.5(2.9-3.9)$ & $3.7(3.3-3.9)$ & $3.5(2.8-4.0)$ & $3.5(3.0-3.9)$ & $3.1(2.5-3.7)^{* *}$ & 0.03 \\
\hline C-reactive protein $\left(\mathrm{mg} \mathrm{dl}^{-1}\right)$ & $0.07(0.03-0.15)$ & $0.06(0.03-0.13)$ & $0.06(0.02-0.12)$ & $0.09(0.04-0.31)$ & $0.06(0.03-0.15)$ & 0.07 \\
\hline Fractional shortening $(\%)$ & $40 \pm 6$ & $41 \pm 5$ & $39 \pm 5$ & $39 \pm 5$ & $39 \pm 6$ & 0.11 \\
\hline $\operatorname{LVEF}(\%)$ & $70 \pm 7$ & $72 \pm 6$ & $70 \pm 7$ & $69 \pm 7$ & $68 \pm 7^{* *}$ & 0.03 \\
\hline LVMI $\left(\mathrm{g} \mathrm{m}^{-2}\right)$ (males) & $143(118-168)$ & $112(82-125)$ & $140(121-167)^{*}$ & $150(108-178)^{*}$ & $159(144-197)^{*}$ & $<0.01$ \\
\hline LVMI ( $\mathrm{g} \mathrm{m}^{-2}$ ) (females) & $104(86-137)$ & $87(78-102)$ & $99(84-125)$ & $126(104-149)^{*}$ & $146(135-165)^{*}$ & $<0.01$ \\
\hline LVH & $115(53)$ & $11(19)$ & $38(54)$ & $30(65)$ & $36(88)$ & $<0.01$ \\
\hline
\end{tabular}

Abbreviations: ACEIs, angiotensin-converting enzyme inhibitors; ARBs, angiotensin II receptor blockers; CKD, chronic kidney disease; DBP, diastolic blood pressure; Hb, hemoglobin; LVEF, left ventricular ejection fraction; LVH, left ventricular hypertrophy; LVMI, left ventricular mass index; SBP, systolic blood pressure.

Values are expressed as the mean \pm s.d., number (percent) or median (interquartile range).

$* P<0.01,{ }^{* *} P<0.05$ vs. CKD stages $1-2$.

Table 2a Clinical characteristics of male patients according to quartile of SUA

\begin{tabular}{|c|c|c|c|c|c|c|}
\hline & All $(\mathrm{n}=117)$ & $\begin{array}{l}\text { 1st Quartile }(\mathrm{n}=29) \\
\left(\mathrm{S} \cup A, 3.7-6.1 \mathrm{mg} \mathrm{dl}^{-1}\right)\end{array}$ & $\begin{array}{l}\text { 2nd Quartile }(\mathrm{n}=29) \\
\left(\mathrm{S} \cup A, 6.2-7.1 \mathrm{mg} \mathrm{dl}^{-1}\right)\end{array}$ & $\begin{array}{l}\text { 3rd Quartile }(\mathrm{n}=30) \\
\left(S \cup A, 7.2-8.0 \mathrm{mgdl}^{-1}\right)\end{array}$ & $\begin{array}{l}\text { 4th Quartile }(\mathrm{n}=29) \\
\left(\mathrm{SUA}, 8.1-11.9 \mathrm{mgdl}^{-1}\right)\end{array}$ & P-values \\
\hline Age & $61(51-70)$ & $57(44-66)$ & $62(52-71)$ & $63(53-73)$ & $61(55-70)$ & 0.10 \\
\hline Hypertension & $96(82)$ & $19(66)$ & $23(79)$ & $25(83)$ & $29(100)$ & $<0.01$ \\
\hline $\mathrm{SBP}(\mathrm{mm} \mathrm{Hg})$ & $138 \pm 21$ & $134 \pm 20$ & $138 \pm 21$ & $135 \pm 23$ & $146 \pm 16$ & 0.06 \\
\hline $\mathrm{DBP}(\mathrm{mm} \mathrm{Hg})$ & $77 \pm 11$ & $75 \pm 9$ & $77 \pm 11$ & $77 \pm 12$ & $80 \pm 10$ & 0.31 \\
\hline Diabetes mellitus & $58(50)$ & $14(48)$ & $16(55)$ & $15(50)$ & $13(45)$ & 0.89 \\
\hline Smoking & $84(72)$ & $19(66)$ & $23(79)$ & $20(67)$ & $22(76)$ & 0.57 \\
\hline Dyslipidemia & $83(71)$ & $21(72)$ & $22(76)$ & $18(60)$ & $22(76)$ & 0.50 \\
\hline ACEls and/or ARBs & $77(66)$ & $16(55)$ & $21(72)$ & $19(63)$ & $21(72)$ & 0.45 \\
\hline Diuretics & $29(25)$ & $5(17)$ & $7(24)$ & $8(27)$ & $9(31)$ & 0.66 \\
\hline Body mass index $\left(\mathrm{kg} \mathrm{m}^{-2}\right)$ & $22.3(20.8-25.7)$ & $21.4(19.7-23.1)$ & $23.1(21.1-27.4)$ & $22.5(20.5-26.4)$ & $22.9(21.4-25.8)$ & 0.14 \\
\hline Proteinuria $\left(\right.$ g day $\left.^{-1}\right)$ & $1.9(0.7-4.9)$ & $2.2(0.7-5.7)$ & $1.6(0.3-5.0)$ & $1.6(1.0-4.3)$ & $2.2(1.0-5.1)$ & 0.56 \\
\hline Serum albumin $\left(\mathrm{g} \mathrm{dl}^{-1}\right)$ & $3.5(2.6-3.9)$ & $3.6(2.6-4.1)$ & $3.7(2.9-4.0)$ & $3.3(2.8-3.8)$ & $3.4(2.5-3.9)$ & 0.77 \\
\hline C-reactive protein $\left(\mathrm{mg} \mathrm{dl}^{-1}\right)$ & $0.08(0.04-0.17)$ & $0.05(0.03-0.13)$ & $0.08(0.05-0.17)$ & $0.09(0.03-0.23)$ & $0.09(0.05-0.27)$ & 0.34 \\
\hline $\mathrm{Hb}\left(\mathrm{gdl}^{-1}\right)$ & $11.8 \pm 2.5$ & $12.8 \pm 2.6$ & $11.9 \pm 2.4$ & $11.3 \pm 2.3$ & $11.1 \pm 2.5^{* *}$ & 0.03 \\
\hline eGFR $\left(\mathrm{ml} \mathrm{min}^{-1}\right.$ per $\left.1.73 \mathrm{~m}^{2}\right)$ & $34.7(17.0-57.2)$ & $59.0(33.7-80.8)$ & $38.9(24.5-58.7)^{*}$ & $25.0(13.7-43.1)^{*}$ & $17.5(11.9-34.7)^{*}$ & $<0.01$ \\
\hline Serum phosphorus (mg dl$\left.{ }^{-1}\right)$ & $3.5(3.2-4.1)$ & $3.3(3.1-3.7)$ & $3.4(3.1-3.8)$ & $3.5(3.2-4.1)$ & $4.0(3.4-4.5)^{*}$ & 0.01 \\
\hline Fractional shortening (\%) & $39 \pm 6$ & $39 \pm 6$ & $39 \pm 6$ & $39 \pm 5$ & $39 \pm 6$ & 0.96 \\
\hline $\operatorname{LVEF}(\%)$ & $69 \pm 7$ & $69 \pm 6$ & $68 \pm 7$ & $69 \pm 6$ & $68 \pm 7$ & 0.97 \\
\hline
\end{tabular}

Abbreviations: ACEls, angiotensin-converting enzyme inhibitors; ARBs, angiotensin II receptor blockers; DBP, diastolic blood pressure; eGFR, estimated glomerular filtration rate; Hb, hemoglobin; LVEF, left ventricular ejection fraction; SBP, systolic blood pressure; SUA, serum uric acid. Values are expressed as the means \pm s.d., number (percent) or median (interquartile range) ${ }^{*} P<0.01,{ }^{* *} P<0.05$ vs. first quartile of SUA.

Table 4 shows the relationship between clinical parameters and LVMI in each sex. In men, univariate linear regression analysis demonstrated that age, hypertension, diabetes mellitus, dyslipidemia, use of ACEIs and/or ARBs, use of diuretics, proteinuria, serum albumin, Hb, serum phosphorus, eGFR and SUA were associated with LVMI. Multivariate analysis showed that use of diuretics was an independent variable 
Table $2 \mathrm{~b}$ Clinical characteristics of female patients according to quartile of SUA

\begin{tabular}{|c|c|c|c|c|c|c|}
\hline & All $(\mathrm{n}=99)$ & $\begin{array}{l}\text { 1st Quartile }(\mathrm{n}=23) \\
\left(S \cup A, 2.7-4.9 \mathrm{mgdt}^{-1}\right)\end{array}$ & $\begin{array}{l}\text { 2nd Quartile }(\mathrm{n}=26) \\
\left(S \cup A, 5.0-6.0 \mathrm{mgdr}^{-1}\right)\end{array}$ & $\begin{array}{l}\text { 3rd Quartile }(\mathrm{n}=23) \\
\left(\mathrm{S} \cup A, 6.1-7.2 \mathrm{mgdl}^{-1}\right)\end{array}$ & $\begin{array}{l}\text { 4th Quartile }(\mathrm{n}=27) \\
\left(\mathrm{SUA}, 7.3-11.7 \mathrm{mgd}^{-1}\right)\end{array}$ & P-values \\
\hline Age & $60(46-69)$ & $53(42-65)$ & $54(40-67)$ & $64(50-71)$ & $67(58-71)^{* *}$ & 0.01 \\
\hline $\mathrm{SBP}(\mathrm{mm} \mathrm{Hg})$ & $128 \pm 19$ & $122 \pm 16$ & $119 \pm 16$ & $136 \pm 19^{* *}$ & $136 \pm 17^{* *}$ & $<0.01$ \\
\hline $\mathrm{DBP}(\mathrm{mm} \mathrm{Hg})$ & $74 \pm 11$ & $73 \pm 9$ & $71 \pm 10$ & $74 \pm 13$ & $77 \pm 10$ & 0.21 \\
\hline Diabetes mellitus & $28(28)$ & $3(13)$ & $5(19)$ & $9(39)$ & $11(40)$ & 0.07 \\
\hline ACEls and/or ARBs & $44(44)$ & $4(17)$ & $9(35)$ & $13(57)$ & $18(67)$ & $<0.01$ \\
\hline Diuretics & $22(22)$ & $1(4)$ & $3(12)$ & $7(30)$ & $11(40)$ & $<0.01$ \\
\hline Body mass index $\left(\mathrm{kg} \mathrm{m}^{-2}\right)$ & $21.8(19.9-24.2)$ & $21.0(19.4-23.1)$ & $21.3(19.5-22.9)$ & $21.9(20.0-25.4)$ & $23.0(20.9-26.7)$ & 0.17 \\
\hline Proteinuria $\left(\right.$ g day $^{-1}$ ) & $1.0(0.4-1.9)$ & $1.1(0.2-1.6)$ & $0.7(0.3-2.2)$ & $1.4(0.6-3.6)$ & $1.1(0.4-1.8)$ & 0.41 \\
\hline Serum albumin $\left(\mathrm{g} \mathrm{dl}^{-1}\right)$ & $3.5(3.1-3.9)$ & $3.5(3.0-3.9)$ & $3.4(3.0-3.6)$ & $3.7(3.1-3.9)$ & $3.7(3.3-4.1)$ & 0.07 \\
\hline C-reactive protein $\left(\mathrm{mg} \mathrm{dl}^{-1}\right)$ & $0.06(0.03-0.13)$ & $0.08(0.04-0.20)$ & $0.05(0.02-0.09)$ & $0.04(0.03-0.07)$ & $0.07(0.03-0.19)$ & 0.22 \\
\hline $\operatorname{LVEF}(\%)$ & $71 \pm 6$ & $71 \pm 6$ & $71 \pm 7$ & $72 \pm 6$ & $71 \pm 7$ & 0.93 \\
\hline
\end{tabular}

Abbreviations: ACEIs, angiotensin-converting enzyme inhibitors; ARBs, angiotensin II receptor blockers; DBP, diastolic blood pressure; eGFR, estimated glomerular filtration rate; Hb, hemoglobin; LVEF, left ventricular ejection fraction; SBP, systolic blood pressure; SUA, serum uric acid.

Values are expressed as the means \pm s.d., number (percent), or median (interquartile range).

${ }^{*} P<0.05,{ }^{*} P<0.01$ vs. first quartile of SUA.
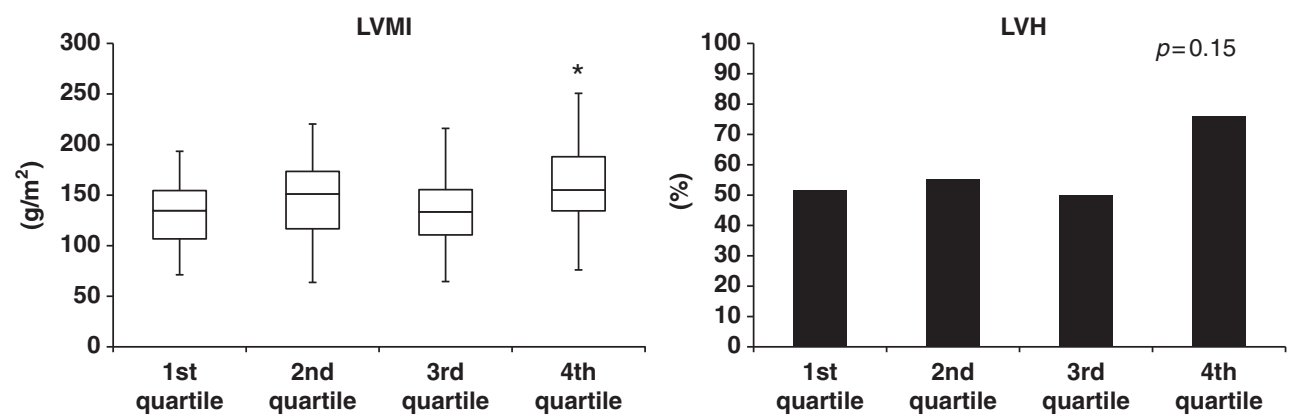

Figure 1 Box-and-whisker plot of left ventricular mass index (LVMI) and the prevalence of left ventricular hypertrophy (LVH) according to quartile of serum uric acid in men. The box represents the 25th, 50th and 75th percentiles; the line inside the box represents the median. ${ }^{*} P<0.01$ vs. quartile 1 .
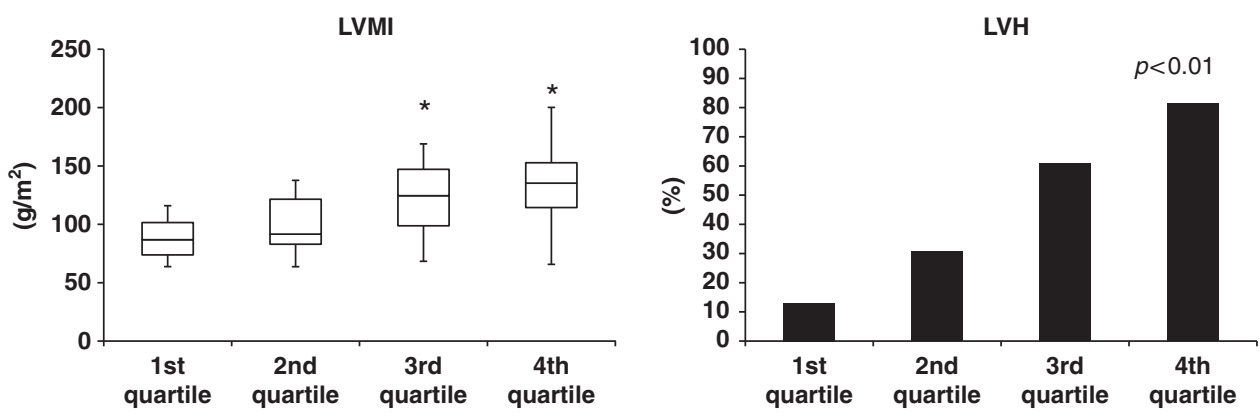

Figure 2 Box-and-whisker plot of left ventricular mass index (LVMI) and the prevalence of left ventricular hypertrophy (LVH) according to quartile of serum uric acid in women. The box represents the 25 th, 50th and 75th percentiles; the line inside the box represents the median. ${ }^{*} P<0.01$ vs. quartile 1 .

associated with LVMI. In women, multivariate linear regression analysis demonstrated that age, hypertension and SUA were independent variables associated with LVMI.

We analyzed the risk factors for LVH for each sex using a logistic regression model, as shown in Table 5. In men, univariate regression analysis showed that age, hypertension, diabetes mellitus, use of ACEIs and/or ARBs, use of diuretics, proteinuria, serum albumin, $\mathrm{Hb}$, serum phosphorus, eGFR and SUA were associated with LVH. In multivariate analysis, only diabetes mellitus, but not SUA and the other variables, was independently associated with LVH. In women, 
multivariate analysis showed that age, hypertension and SUA were independently associated with $\mathrm{LVH}$.

\section{DISCUSSION}

We observed a high prevalence of cardiac hypertrophy among CKD patients in this study compared with a previous report showing $\mathrm{LVH}$ prevalence ranging from 36 to $41 \%$ among hypertensive patients. ${ }^{34}$ The prevalence of cardiac hypertrophy was significantly higher with advancing CKD stage. In women, LVMI and the prevalence of LVH were significantly higher with ascending quartiles by SUA level. When male and female subjects were analyzed separately by multivariate analysis, elevated SUA levels were identified as an independent risk factor for both LVH and LVMI in females, whereas in males there was

Table 3 Clinical characteristics of female patients $<45$ years old and $\geqslant 45$ years old

\begin{tabular}{|c|c|c|c|}
\hline & $<45(\mathrm{n}=21)$ & $\geqslant 45(n=78)$ & P-values \\
\hline Age & $39(35-42)$ & $65(56-71)$ & $<0.01$ \\
\hline Hypertension & $5(24)$ & $56(72)$ & $<0.01$ \\
\hline $\mathrm{SBP}(\mathrm{mm} \mathrm{Hg})$ & $116 \pm 14$ & $132 \pm 18$ & $<0.01$ \\
\hline DBP (mm Hg) & $73 \pm 11$ & $74 \pm 11$ & 0.70 \\
\hline Diabetes mellitus & $1(5)$ & $27(35)$ & $<0.01$ \\
\hline Smoking & $1(5)$ & $17(22)$ & 0.04 \\
\hline Dyslipidemia & $6(29)$ & $55(71)$ & $<0.01$ \\
\hline ACEIs and/or ARBs & $6(29)$ & $38(49)$ & 0.09 \\
\hline Diuretics & $0(0)$ & $22(28)$ & $<0.01$ \\
\hline Body mass index $\left(\mathrm{kg} \mathrm{m}^{-2}\right)$ & $20.7(19.3-23.5)$ & $21.9(20.1-24.6)$ & 0.20 \\
\hline Proteinuria $\left(\right.$ g day $^{-1}$ ) & $0.8(0.3-1.7)$ & $1.1(0.4-2.2)$ & 0.27 \\
\hline Serum albumin $\left(\mathrm{g} \mathrm{dl}^{-1}\right)$ & $3.6(3.3-3.8)$ & $3.5(3.1-3.9)$ & 0.68 \\
\hline C-reactive protein $\left(\mathrm{mg} \mathrm{dl}^{-1}\right)$ & $0.06(0.03-0.09)$ & $0.06(0.03-0.14)$ & 0.79 \\
\hline $\mathrm{Hb}\left(\mathrm{g} \mathrm{dl}^{-1}\right)$ & $11.3 \pm 1.7$ & $10.9 \pm 1.9$ & 0.45 \\
\hline eGFR $\left(\mathrm{ml} \mathrm{min}{ }^{-1}\right.$ per $\left.1.73 \mathrm{~m}^{2}\right)$ & $74.0(43.7-85.2)$ & $36.7(17.4-61.2)$ & $<0.01$ \\
\hline Serum phosphorus (mg dl-1) & $3.5(3.3-3.9)$ & $3.9(3.5-4.2)$ & 0.07 \\
\hline SUA (mg dl-1) & $5.1(4.2-5.5)$ & $6.4(5.4-7.5)$ & $<0.01$ \\
\hline Fractional shortening (\%) & $39 \pm 6$ & $41 \pm 5$ & 0.24 \\
\hline LVEF (\%) & $70 \pm 6$ & $72 \pm 6$ & 0.33 \\
\hline LVMI $\left(\mathrm{g} \mathrm{m}^{-2}\right)$ & $82(71-92)$ & $119(93-144)$ & $<0.01$ \\
\hline LVH & $2(10)$ & $45(58)$ & $<0.01$ \\
\hline
\end{tabular}

Abbreviations: ACEIs, angiotensin-converting enzyme inhibitors; ARBs, angiotensin II receptor blockers; DBP, diastolic blood pressure; eGFR, estimated glomerular filtration rate;

$\mathrm{Hb}$, hemoglobin; LVEF, left ventricular ejection fraction; LVH, left ventricular hypertrophy;

LVMI, left ventricular mass index; SBP, systolic blood pressure; SUA, serum uric acid.

Values are expressed as the means \pm s.d., number (percent), or median (interquartile range).

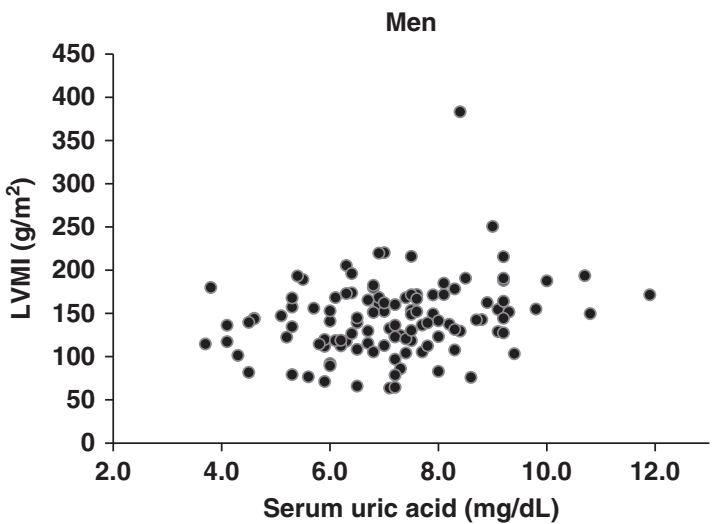

no significant relationship between SUA levels and cardiac hypertrophy.

This study did not clarify the mechanisms by which increased SUA levels caused cardiac hypertrophy. The role of SUA in the development of $\mathrm{CV}$ complications has not been fully investigated; however, some potential mechanisms have been proposed. It has been demonstrated that SUA impairs nitric oxide generation and induces endothelial dysfunction and smooth muscle cell proliferation. ${ }^{35,36}$ It is also reported that SUA increases plasma levels of inflammatory mediators such as tumor necrosis factor alpha, ${ }^{37}$ and potentially stimulates mitogen-activated protein kinases, ${ }^{38}$ which are known to induce cardiac hypertrophy. ${ }^{39,40}$ Moreover, uric acid appears to activate the renin-angiotensin system, thereby leading to the development of LVH. ${ }^{41,42}$ Given these findings, cardiac hypertrophy may be directly attributable, at least in part, to increased SUA, via stimulation of endothelial dysfunction, smooth muscle cell proliferation, inflammation and activation of the renin-angiotensin system.

A recent study demonstrated that SUA levels were independently associated with CV morbidity, and that this association was stronger for patients in more advanced CKD stages. ${ }^{20}$ In another recent study, an increased ratio of observed to predicted LVM was shown to be independently related to adverse $\mathrm{CV}$ events in patients with $\mathrm{CKD}$ stages 3-5. ${ }^{11}$ Another report demonstrated that the combination of hyperuricemia with $\mathrm{LVH}$ is a powerful independent predictor for $\mathrm{CV}$ disease. The authors of that report speculated that the association between SUA and CV events in hypertensive patients might result from a direct association between SUA and LVMI. ${ }^{25}$ Allopurinol has been found to decrease oxidative stress and to improve endothelial function in metabolic syndrome. ${ }^{43}$ On the basis of these findings, SUA appears to contribute to the development of cardiac hypertrophy and CV events.

The sex-related effects of SUA on CV disease and cardiac hypertrophy are conflicting. This study demonstrated an association between SUA and cardiac hypertrophy only in female subjects. This finding agrees with previous observations in hypertensive patients. ${ }^{22,23}$ Furthermore, the First National Health and Nutrition Examination Survey epidemiologic follow-up studies demonstrated a relationship between SUA and mortality (all-causes and due to CV events) only in women, ${ }^{17}$ and found that the association between SUA and CV mortality was stronger in women than in men. ${ }^{14}$ Given these findings, the influence of SUA on CV disease appears to be greater in women than in men. Although the reasons for these sex differences remain unclear, sex hormones may have a role. ${ }^{44}$ This study found that female subjects $\geqslant 45$ years of age, who may be post-menopausal,

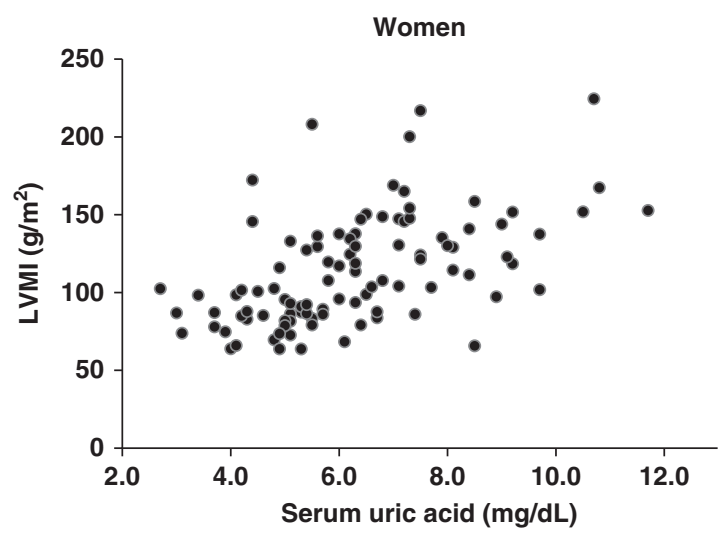

Figure 3 Relationship between serum uric acid and left ventricular mass index (LVMI) in men and women. A full color version of this figure is available at the Hypertension Research journal online. 
Table 4 Relationship by sex between left ventricular mass index and clinical parameters

\begin{tabular}{|c|c|c|c|c|c|c|c|c|}
\hline \multirow[b]{3}{*}{ Variables } & \multicolumn{4}{|c|}{ Men } & \multicolumn{4}{|c|}{ Women } \\
\hline & \multicolumn{2}{|c|}{ Univariate } & \multicolumn{2}{|c|}{ Multivariate } & \multicolumn{2}{|c|}{ Univariate } & \multicolumn{2}{|c|}{ Multivariate } \\
\hline & $\beta$ & P-values & $\beta$ & P-values & $\beta$ & P-values & $\beta$ & P-values \\
\hline Age (years) & 0.27 & $<0.01$ & 0.20 & 0.06 & 0.42 & $<0.01$ & 0.21 & 0.02 \\
\hline Hypertension & 0.39 & $<0.01$ & 0.13 & 0.25 & 0.61 & $<0.01$ & 0.26 & 0.03 \\
\hline Dyslipidemia & 0.20 & 0.03 & -0.05 & 0.57 & 0.15 & 0.13 & & \\
\hline ACEls and/or ARBs & 0.33 & $<0.01$ & -0.004 & 0.97 & 0.44 & $<0.01$ & 0.08 & 0.42 \\
\hline Diuretics & 0.37 & $<0.01$ & 0.24 & 0.02 & 0.36 & $<0.01$ & 0.01 & 0.92 \\
\hline Body mass index $\left(\mathrm{kg} \mathrm{m}^{-2}\right)$ & 0.09 & 0.35 & & & 0.20 & 0.05 & & \\
\hline Proteinuria $\left(\mathrm{g} \mathrm{day}^{-1}\right.$ ) & 0.20 & 0.03 & 0.02 & 0.89 & 0.26 & $<0.01$ & 0.15 & 0.08 \\
\hline eGFR $\left(\mathrm{ml} \mathrm{min}{ }^{-1}\right.$ per $\left.1.73 \mathrm{~m}^{2}\right)$ & -0.45 & $<0.01$ & -0.14 & 0.34 & -0.47 & $<0.01$ & 0.05 & 0.66 \\
\hline Serum uric acid $\left(\mathrm{mg} \mathrm{dl}^{-1}\right)$ & 0.25 & $<0.01$ & 0.03 & 0.78 & 0.53 & $<0.01$ & 0.27 & 0.02 \\
\hline
\end{tabular}

Abbreviations: ACEIs, angiotensin-converting enzyme inhibitors; ARBs, angiotensin II receptor blockers; eGFR, estimated glomerular filtration rate; Hb, hemoglobin.

Table 5 ORs by sex for left ventricular hypertrophy

\begin{tabular}{|c|c|c|c|c|c|c|c|c|c|c|c|c|}
\hline \multirow[b]{3}{*}{ Variables } & \multicolumn{6}{|c|}{ Men } & \multicolumn{6}{|c|}{ Women } \\
\hline & \multicolumn{3}{|c|}{ Univariate } & \multicolumn{3}{|c|}{ Multivariate } & \multicolumn{3}{|c|}{ Univariate } & \multicolumn{3}{|c|}{ Multivariate } \\
\hline & $O R$ & $95 \% \mathrm{Cl}$ & P-values & $O R$ & $95 \% \mathrm{Cl}$ & P-values & $O R$ & $95 \% \mathrm{Cl}$ & P-values & OR & $95 \% \mathrm{Cl}$ & P-values \\
\hline Age (years) & 1.04 & $1.01-1.07$ & 0.01 & 1.03 & $0.98-1.10$ & 0.22 & 1.11 & $1.06-1.16$ & $<0.01$ & 1.13 & $1.06-1.23$ & $<0.01$ \\
\hline Hypertension & 20.9 & $5.59-136.5$ & $<0.01$ & 5.84 & $0.97-50.07$ & 0.054 & 30.2 & $9.34-137.4$ & $<0.01$ & 7.38 & $1.20-57.37$ & 0.03 \\
\hline Diabetes mellitus & 9.36 & $4.06-23.3$ & $<0.01$ & 4.43 & $1.39-15.42$ & 0.01 & 6.75 & $2.55-20.3$ & $<0.01$ & 1.42 & $0.26-8.39$ & 0.68 \\
\hline Smoking & 1.45 & $0.64-3.29$ & 0.37 & & & & 2.63 & $0.93-8.20$ & 0.07 & & & \\
\hline Dyslipidemia & 2.24 & $0.999-5.11$ & 0.05 & & & & 2.42 & $1.06-5.73$ & 0.04 & 0.72 & $0.15-3.09$ & 0.66 \\
\hline ACEls and/or ARBs & 6.22 & $2.74-14.89$ & $<0.01$ & 1.34 & $0.41-4.33$ & 0.62 & 7.11 & $3.00-17.93$ & $<0.01$ & 3.92 & $0.87-20.25$ & 0.07 \\
\hline Diuretics & 9.49 & $3.06-41.85$ & $<0.01$ & 3.11 & $0.71-17.34$ & 0.14 & 5.33 & $1.89-17.60$ & $<0.01$ & 0.81 & $0.13-4.89$ & 0.82 \\
\hline Body mass index $\left(\mathrm{kg} \mathrm{m}^{-2}\right)$ & 0.98 & $0.89-1.08$ & 0.70 & & & & 1.10 & $0.99-1.22$ & 0.07 & & & \\
\hline Proteinuria (g day ${ }^{-1}$ ) & 1.29 & $1.11-1.54$ & $<0.01$ & 0.97 & $0.75-1.28$ & 0.83 & 1.21 & $0.99-1.53$ & 0.06 & & & \\
\hline Serum albumin & 0.33 & $0.18-0.57$ & $<0.01$ & 0.74 & $0.25-2.16$ & 0.59 & 0.91 & $0.52-1.60$ & 0.75 & & & \\
\hline C-reactive protein $\left(\mathrm{mg} \mathrm{dl}^{-1}\right)$ & 0.70 & $0.23-1.93$ & 0.48 & & & & 2.06 & $0.91-12.4$ & 0.09 & & & \\
\hline $\mathrm{Hb}\left(\mathrm{g} \mathrm{dl}^{-1}\right)$ & 0.67 & $0.55-0.80$ & $<0.01$ & 0.96 & $0.70-1.33$ & 0.81 & 0.66 & $0.51-0.83$ & $<0.01$ & 0.77 & $0.48-1.22$ & 0.12 \\
\hline Serum phosphorus (mg dl-1) & 2.88 & $1.57-5.82$ & $<0.01$ & 1.46 & $0.59-4.00$ & 0.43 & 3.05 & $1.56-6.83$ & $<0.01$ & 1.36 & $0.41-5.51$ & 0.28 \\
\hline eGFR ( $\mathrm{ml} \mathrm{min}{ }^{-1}$ per $1.73 \mathrm{~m}^{2}$ ) & 0.96 & $0.94-0.98$ & $<0.01$ & 1.00 & $0.96-1.04$ & 0.99 & 0.96 & $0.95-0.98$ & $<0.01$ & 1.03 & 0.99-1.07 & 0.12 \\
\hline Serum uric acid $\left(\mathrm{mg} \mathrm{dl}^{-1}\right)$ & 1.29 & $1.01-1.69$ & 0.04 & 1.11 & $0.74-1.72$ & 0.62 & 2.26 & $1.63-3.34$ & $<0.01$ & 1.91 & $1.14-3.61$ & 0.03 \\
\hline
\end{tabular}

Abbreviations: ACEIs, angiotensin-converting enzyme inhibitors; ARBs, angiotensin II receptor blockers; $\mathrm{Cl}$, confidence interval; eGFR, estimated glomerular filtration rate; Hb, hemoglobin; OR, odds ratio.

had higher SUA levels, and a higher prevalence of $\mathrm{LVH}$, compared with those $<45$ years of age. Given that female subjects $\geqslant 45$ years of age had lower kidney function compared with those $<45$ years of age, this observation may be partly attributable to the higher prevalence of advanced CKD stages in female subjects $\geqslant 45$ years of age. In postmenopausal women, increased SUA levels may result from menopause-related metabolic changes, and might correlate with an increased risk of coronary artery disease. ${ }^{45}$ It is possible that the role of SUA as a risk for CV disease becomes more obvious for patients with a generally lower risk profile, such as women. ${ }^{22}$
This study has some limitations. First, the sample size was relatively small. A larger cohort study will be needed to avoid study bias and to document more precisely the relationship between SUA and cardiac hypertrophy. Second, most of our subjects were treated with antihypertensive agents: $55 \%$ of subjects received ACEIs and/or ARBs, which are known to prevent cardiac hypertrophy. ${ }^{46}$ However, univariate analysis showed that use of ACEIs and/or ARBs was associated with increased LVMI and higher prevalence of LVH in both sexes. It seems reasonable that ACEIs and/or ARBs were predominantly used for patients with cardiac hypertrophy. 
Multivariate analysis showed that the use of diuretics was an independent variable associated with LVMI in men. This finding may reflect the tendency for patients with higher LVMI to receive diuretics more often.

In conclusion, our results show an independent association between SUA levels and LVH and LVMI in female subjects, but not in male subjects. This finding suggests that an association between SUA levels and the development of LVH and LVMI is more likely in women than in men.

\section{CONFLICT OF INTEREST}

The authors declare no conflict of interest.

1 Herzog CA, Asinger RW, Berger AK, Charytan DM, Díez J, Hart RG, Eckardt KU, Kasiske BL, McCullough PA, Passman RS, DeLoach SS, Pun PH, Ritz E. Cardiovascular disease in chronic kidney disease. A clinical update from Kidney Disease Improving Global Outcomes (KDIGO). Kidney Int 2011; 80: 572-586.

2 Casale PN, Devereux RB, Milner M, Zullo G, Harshfield GA, Pickering TG, Laragh JH. Value of echocardiographic measurement of left ventricular mass in predicting cardiovascular morbid events in hypertensive men. Ann Intern Med 1986; 105: 173-178.

3 Koren MJ, Devereux RB, Casale PN, Savage DD, Laragh JH. Relation of left ventricula mass and geometry to morbidity and mortality in uncomplicated essential hypertension. Ann Intern Med 1991; 114: 345-352.

4 Levy D, Garrison RJ, Savage DD, Kannel WB, Castelli WP. Left ventricular mass and incidence of coronary heart disease in an elderly cohort. The Framingham Heart Study. Ann Intern Med 1989; 110: 101-117.

5 Levy D, Garrison RJ, Savage DD, Kannel WB, Castelli WP. Prognostic implications of echocardiographically determined left ventricular mass in the Framingham Heart Study. N Engl J Med 1990; 322: 1561-1566.

6 Levin A, Singer J, Thompson CR, Ross H, Lewis M. Prevalent left ventricular hypertrophy in the predialysis population: identifying opportunities for intervention. Am J Kidney Dis 1996; 27: 347-354.

7 Tucker B, Fabbian F, Giles M, Thuraisingham RC, Raine AE, Baker LR. Left ventricular hypertrophy and ambulatory blood pressure monitoring in chronic renal failure. Nephrol Dial Transplant 1997; 12: 724-728.

8 Levin A, Thompson CR, Ethier J, Carlisle EJ, Tobe S, Mendelssohn D, Burgess E, Jindal K, Barrett B, Singer J, Djurdjev O. Left ventricular mass index increase in early renal disease: impact of decline in hemoglobin. Am J Kidney Dis 1999; 34: 125-134.

9 McMahon LP, Roger SD, Levin ASlimheart Investigators Group. Development, preven tion, and potential reversal of left ventricular hypertrophy in chronic kidney disease. J Am Soc Nephrol 2004; 15: 1640-1647.

10 Cioffi G, Tarantini L, Frizzi R, Stefenelli C, Russo TE, Selmi A, Toller C, Furlanello F, de Simone G. Chronic kidney disease elicits excessive increase in left ventricular mass growth in patients at increased risk for cardiovascular events. J Hypertens 2011; 29: 565-573

11 Chen SC, Chang JM, Liu WC, Chen YY, Chen LI, Huang JC, Yang TK, Su HM, Chen HC. The ratio of observed to predicted left ventricular mass is independently associated with increased cardiovascular events in patients with chronic kidney disease. Hypertens Res 2012; 35: 832-838.

12 Paoletti E, Bellino D, Cassottana P, Rolla D, Cannella G. Left ventricular hypertrophy in nondiabetic predialysis CKD. Am J Kidney Dis 2005; 46: 320-327.

13 Nardi E, Palermo A, Mulè G, Cusimano P, Cottone S, Cerasola G. Left ventricular hypertrophy and geometry in hypertensive patients with chronic kidney disease. J Hypertens 2009; 27: 633-641.

14 Fang J, Alderman MH. Serum uric acid and cardiovascular mortality the NHANES I epidemiologic follow-up study, 1971-1992.National Health and Nutrition Examination Survey. JAMA 2000; 283: 2404-2410.

15 Bengtsson C, Lapidus L, Stendahl C, Waldenström J. Hyperuricaemia and risk of cardiovascular disease and overall death. A 12-year follow-up of participants in the population study of women in Gothenburg, Sweden. Acta Med Scand 1988; 224: 549-555.

16 Klein R, Klein BE, Cornoni JC, Maready J, Cassel JC, Tyroler HA. Serum uric acid. Its relationship to coronary heart disease risk factors and cardiovascular disease, Evans County, Georgia. Arch Intern Med 1973; 132: 401-410.

17 Freedman DS, Williamson DF, Gunter EW, Byers T. Relation of serum uric acid to mortality and ischemic heart disease. The NHANES I epidemiologic follow-up study. Am J Epidemiol 1995; 141: 637-644.

18 Verdecchia P, Schillaci G, Reboldi G, Santeusanio F, Porcellati C, Brunetti P. Relation between serum uric acid and risk of cardiovascular disease in essential hypertension. The PIUMA study. Hypertension 2000; 36: 1072-1078.

19 Alderman $\mathrm{MH}$, Cohen H, Madhavan S, Kivlighn S. Serum uric acid and cardiovascular events in successfully treated hypertensive patients. Hypertension 1999; 34: 144-150.

20 Neri L, Rocca Rey LA, Lentine KL, Hinyard LJ, Pinsky B, Xiao H, Dukes J, Schnitzler MA. Joint association of hyperuricemia and reduced GFR on cardiovascular morbidity: a historical cohort study based on laboratory and claims data from a national insurance provider. Am J Kidney Dis 2011; 58: 398-408.

21 Liu WC, Hung CC, Chen SC, Yeh SM, Lin MY, Chiu YW, Kuo MC, Chang JM, Hwang SJ, Chen HC. Association of hyperuricemia with renal outcomes, cardiovascular disease, and mortality. Clin J Am Soc Nephrol 2012; 7: 541-548.

22 Viazzi F, Parodi D, Leoncini G, Parodi A, Falqui V, Ratto E, Vettoretti S, Bezante GP Del Sette M, Deferrari G, Pontremoli R. Serum uric acid and target organ damage in primary hypertension. Hypertension 2005; 45: 991-996.

23 Matsumura K, Ohtsubo T, Oniki H, Fujii K, lida M. Gender-related association of serum uric acid and left ventricular hypertrophy in hypertension. Circ J 2006; 70: 885-888.

24 Mitsuhashi H, Yatsuya H, Matsushita K, Zhang H, Otsuka R, Muramatsu T, Takefuji S Hotta Y, Kondo T, Murohara T, Toyoshima H, Tamakoshi K. Uric acid and left ventricular hypertrophy in Japanese men. Circ J 2009; 73: 667-672.

25 Iwashima Y, Horio T, Kamide K, Rakugi H, Ogihara T, Kawano Y. Uric acid, left ventricular mass index, and risk of cardiovascular disease in essential hypertension. Hypertension 2006; 47: 195-202.

26 Kurata A, Shigematsu Y, Higaki J. Sex-related differences in relations of uric acid to left ventricular hypertrophy and remodeling in Japanese hypertensive patients. Hypertens Res 2005; 28: 133-139.

27 Chonchol M, Shlipak MG, Katz R, Sarnak MJ, Newman AB, Siscovick DS, Kestenbaum B, Carney JK, Fried LF. Relationship of uric acid with progression of kidney disease. Am J Kidney Dis 2007; 50: 239-247.

28 Caliskan Y, Gorgulu N, Yelken B, Akturk F, Yazici H, Turkmen A, Sever MS. Serum uric acid level is associated with cardiac hypertrophy in renal transplant recipients. Clin Transplant 2011; 25: 368-374

29 Chen SC, Chang JM, Yeh SM, Su HM, Chen HC. Association of uric acid and left ventricular mass index with renal outcomes in chronic kidney disease. Am J Hypertens 2013; 26: 243-249.

30 Matsuo S, Imai E, Horio M, Yasuda Y, Tomita K, Nitta K, Yamagata K, Tomino Y, Yokoyama $\mathrm{H}$, Hishida A. Collaborators developing the Japanese equation for estimated GFR: revised equations for estimated GFR from serum creatinine in Japan. Am J Kidney Dis 2009; 53: 982-992.

31 Devereux RB, Reichek N. Echocardiographic determination of left ventricular mass in man. Anatomic validation of the method. Circulation 1977; 55: 613-618.

32 Wang Y, Moss J, Thisted R. Predictors of body surface area. J Clin Anesth 1992; 4: 4-10.

33 Hammond IW, Devereux RB, Alderman MH, Lutas EM, Spitzer MC, Crowley JS, Laragh JH. The prevalence and correlates of echocardiographic left ventricular hypertrophy among employed patients with uncomplicated hypertension. J Am Coll Cardiol 1986; 7: 639-650.

34 Cuspidi C, Sala C, Negri F, Mancia G, Morganti Altalian Society of Hypertension. Prevalence of left-ventricular hypertrophy in hypertension: an updated review of echocardiographic studies. J Hum Hypertens 2012; 26: 343-349.

35 Rao GN, Corson MA, Berk BC. Uric acid stimulates vascular smooth muscle cell proliferation by increasing platelet-derived growth factor A-chain expression. J Biol Chem 1991; 266: 8604-8608.

36 Khosla UM, Zharikov S, Finch JL, Nakagawa T, Roncal C, Mu W, Krotova K, Block ER, Prabhakar S, Johnson RJ. Hyperuricemia induces endothelial dysfunction. Kidney Int 2005; 67: 1739-1742.

37 Netea MG, Kullberg BJ, Blok WL, Netea RT, van der Meer JW. The role of hyperuricemia in the increased cytokine production after lipopolysaccharide challenge in neutropenic mice. Blood 1997; 89: 577-582.

38 Watanabe S, Kang DH, Feng L, Nakagawa T, Kanellis J, Lan H, Mazzali M, Johnson RJ. Uric acid, hominoid evolution, and the pathogenesis of salt-sensitivity. Hypertension 2002; 40: 355-360.

39 Yokoyama T, Nakano M, Bednarczyk JL, Mclntyre BW, Entman M, Mann DL. Tumor necrosis factor-alpha provokes a hypertrophic growth response in adult cardiac myocytes. Circulation 1997; 95: 1247-1252.

40 Sugden PH, Clerk A. "Stress-responsive" mitogen-activated protein kinases (c-Jun $\mathrm{N}$-terminal kinases and p38 mitogen-activated protein kinases) in the myocardium Circ Res 1998; 83: 345-352.

41 Agabiti-Rosei E, Muiesan ML, Salvetti M. Evaluation of subclinical target organ damage for risk assessment and treatment in the hypertensive patients: left ventricular hypertrophy. J Am Soc Nephrol 2006; 17: S104-S108.

42 Nakahara T, Takata Y, Hirayama Y, Asano K, Adachi H, Shiokawa G, Sumi T, Ogawa T, Yamashina A. Left ventricular hypertrophy and geometry in untreated essential hypertension is associated with blood levels of aldosterone and procollagen type III amino-terminal peptide. Circ J 2007; 71: 716-721.

43 Yiginer O, Ozcelik F, Inanc T, Aparci M, Ozmen N, Cingozbay BY, Kardesoglu E, Suleymanoglu S, Sener G, Cebeci BS. Allopurinol improves endothelial function and reduces oxidant-inflammatory enzyme of myeloperoxidase in metabolic syndrome. Clin Res Cardiol 2008; 97: 334-340.

44 Levine W, Dyer AR, Shekelle RB, Schoenberger JA, Stamler J. Serum uric acid and 11.5-year mortality of middle-aged women: findings of the Chicago Heart Association Detection Project in Industry. J Clin Epidemiol 1989; 42: 257-267.

45 Wingrove CS, Walton C, Stevenson JC. The effect of menopause on serum uric acid levels in non-obese healthy women. Metabolism 1998; 47: 435-438.

46 Cowan BR, Young AA, Anderson C, Doughty RN, Krittayaphong R, Lonn E, Marwick TH, Reid CM, Sanderson JE, Schmieder RE, Teo K, Wadham AK, Worthley SG, Yu CM, Yusuf S, Jennings GLONTARGET Investigators. Left ventricular mass and volume with telmisartan, ramipril, or combination in patients with previous atherosclerotic events or with diabetes mellitus (from the ONgoing Telmisartan Alone and in Combination With Ramipril Global Endpoint Trial [ONTARGET]). Am J Cardiol 2009; 104: 1484-1489. 